\title{
Thermo-mechanical modeling of the temperature dependent forming behavior of thermoplastic prepregs
}

\author{
Jean-Paul Ziegs ${ }^{1}$, Daniel Weck ${ }^{2}$, Maik Gude ${ }^{3}$, and Markus Kästner ${ }^{1}$ \\ ${ }^{1}$ Institute of Solid Mechanics \\ ${ }^{2} \mathrm{TU}$ Dresden \\ ${ }^{3} \mathrm{TU}$ Dresden Institute of Lightweight Engineering and Polymer Technology
}

September 1, 2020

\begin{abstract}
Numerical optimization of the manufacturing process of hybrid lightweight struc- tures consisting of fiber-reinforced plastics (FRP) is of high importance. It can reduce the time to market and can also avoid the production of costly prototypes. To model the considered thermoforming process, the temperature dependent defor- mation mechanisms have to be characterized and modeled within a finite element framework. An industry-oriented approach based on the parameterization of a material model implemented in LS-DYNA is introduced. The accordingly parameterized material model for the FRP is eventually applied in the simulation of thermoforming processes to show the influence of process and material parameters on the forming behavior of the thermoplastic prepreg.
\end{abstract}

\section{Hosted file}

Paper_Ziegs-AMARETO.pdf available at https://authorea.com/users/355453/articles/ 478675-thermo-mechanical-modeling-of-the-temperature-dependent-forming-behavior-ofthermoplastic-prepregs

Hosted file

Paper_Ziegs_all-Files.zip available at https://authorea.com/users/355453/articles/ 478675-thermo-mechanical-modeling-of-the-temperature-dependent-forming-behavior-ofthermoplastic-prepregs 